\title{
Molecular Identification and Diversity of Yeasts Associated with Apis cerana Foraging on Flowers of Jatropha integerrima
}

ADI BASUKRIADI*, WELLYZAR SJAMSURIDZAL AND BANGGA BERISTAMA PUTRA

Department of Biology, Faculty of Mathematics and Natural Sciences, Universitas Indonesia,

There are only a few reports from tropical countries, and none from Indonesia, on yeasts associated with the Asiatic honeybee, $A p t s$ cerana. Here we report on yeasts associated with $A$. cerana foraging on flowers of Jatropha integerrima in the campus of the Universitas

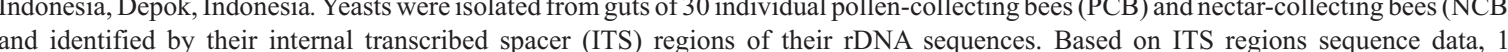

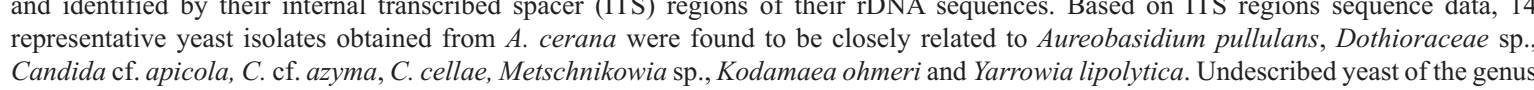
Candida cf. apicola, C. c. c. azyma, C. cellae, Metschnikowia sp., Kodamaee ohmeri and Yarrowia lipolytica. Undescribed yeast of the genus
of Metschnikowia was also discovered in this study. At present, we assume there is association between $C$. cf. apicola and specties closely elated to C. cellae with A. cerana. Yeasts species associated with PCB differ from those found in NCB, indicating that PCB and NCB posses different and specific yeasts communitites. Some yeasts species isolated from A. cerana show a low de
species. Our study sheds light on the detection of several new taxa of yeasts associated with $A$. cerana.

Key words: Apis cerana, yeasts, diversity, ITS regions of rDNA

The association between yeasts and insects has been extensively reported by many scientists over the last three decades (Batra et al. 1973; Shandu and Waraich 1985; Lachance et al. 1990; Hagler et al. 1993; Lachance et al. 1998; Lachance et al. 2001a; Teixeira et al. 2003; Zacchi and Vaughan-Martini 2003; Such and Blackwell 2004; Lachance et al. 2005; Such et al. 2005; de Vega et al. 2009; Unal et al. 2009). Insect gut habitats harbour an astonishing diversity of previously undescribed yeasts (Suh et al. 2005). Their finding suggests that many unknown yeasts are waiting to be found.

Many scientists working in temperate countries have reported the functional relationships between honeybees and their associated yeasts, but the reports on yeast associated with honeybees in tropical countries are scarce. Most of honeybee-associated yeasts studied were isolated from Apis mellifera, with only one study was reporting on $A$. cerana (Sandhu and Waraich 1985).

Since relatively little is known about the association of yeasts and the honeybee in tropical countries, we investigated yeasts associated with $A$. cerana collected on the campus of the University of Indonesia, Depok, Indonesia. Apis cerana or the Asiatic honeybee (or the Eastern honeybee) is distributed widely in Indonesia and is native to most parts of Asia. This local honeybee can be found living in the wild or domesticated. This honeybee is one out of five species of honeybees native to Indonesia (Hadisoesilo 2001).

In this study, we examined yeast diversity from samples isolated from the guts of pollen-collecting bees (PCB) and nectar-collecting bees $(\mathrm{NCB})$ of $A$. cerana foraging on flowers of $J$. integerrima on the campus of the University of Indonesia. Yeast identification was determined based on sequence data of internal transcribed spacer (ITS) regions of ribosomal DNA. Phylogenetic analysis of closely related

${ }^{*}$ Coresponding author: Phone: $+62-21-7866868$,
Fax: $+62-21-7270012$, Email: Abasukriadi@yahoo.com species is possible by the use of the region spanning the two intergenic transcribed spacers (ITS1 \& ITS2) and the 5.8S ribosomal subunit. The ITS region is subdivided into the ITS1 region which separates the conserved $18 \mathrm{~S}$ and the $5.8 \mathrm{~S}$ rRNA genes (James et al. 1996). The ITS2 region is found between the $5.8 \mathrm{~S}$ and $28 \mathrm{~S}$ rRNA genes. The ITS regions are less conserved as a result of fewer evolutionary constraints, and hence they can be used to discriminate between yeast species (Kurtzman 2001). Intergenic transcribed spacers divergence in yeast species is marked, species being clearly separated by at least $1 \%$ sequence diversity (Sugita et al. 1999; Caligiorne et al. 2005).

\section{MATERIALS AND METHODS}

Collection of Honeybees. Sampling of 30 honeybees from the Universitas Indonesia (UI), Depok, campus was conducted between January and April 2009. Collections of A. cerana were made repeatedly at different localities on the UI campus. Thirty adult worker bees of $A$. cerana collecting pollen $(\mathrm{PCB})$ and nectar $(\mathrm{NCB})$ were captured when foraging on flowers of $J$. integerrima. The bees were ollected in sterile polyethylene bags (each individual adult worker honeybee was placed in a separate plastic bag), brought to the laboratory, and processed immediately. The bees were kept in the freezer after collection to make them inactive and easy to handle. The bees were kept alive until dissection.

Yeast Isolation and Culture. Bees are surface disinfected by submerging in $5.25 \%(\mathrm{v} / \mathrm{v}) \mathrm{NaOCl}$ solution for $1 \mathrm{~min}$ to disinfect the surface. The $\mathrm{NaOCl}$ wash was followed by a $0.7 \%(\mathrm{w} / \mathrm{v}) \mathrm{NaCl}$ rinse and the rinse-liquid was then plated on yeast extract agar $50 \%$ glucose (YAG $50 \%$ ) supplemented

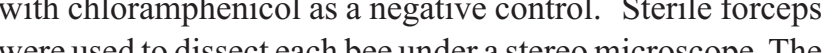
bee gut was removed aseptically and teo merod to bee gut was removed aseptically and transferred to mortar crushed in the sterile with MilliQ water using a pestle. The suspension then was transferred to an Erlenmeyer flask containing $99 \mathrm{~mL}$ sterile water and vortexed for $1 \mathrm{~min}$ to homogenize the suspension. The suspension was filtere using Whatman filter paper and then the filter paper was transferred to YAG $50 \%$ plate. The filtrate was again filtere on a millipore membrane (pore size $0.45 \mu \mathrm{m}$ ) using vacuum pump. The millipore membrane was transferred to YAG $50 \%$ plate. Plates were incubated at room temperature $\left(26-28^{\circ} \mathrm{C}\right)$, and after three days all single colonies were picked up using sterile toothpicks and put into colony libraries. The representative colonies of each morphologica type were purified at least two times on yeast malt extrac Agar (YMA) plates supplemented with chloramphenico $\left(100 \mathrm{mg} \mathrm{L}^{-1}\right)$ and maintained on potato dextrose agar (PDA) slants. The cultures from this study were deposited in the University of Indonesia Culture Collection (UICC).

Amplification of ITS Regions. A cell suspension with loopful of yeast cells in $250 \mu \mathrm{L}$ of sterile MilliQ water was boiled for $20 \mathrm{~min}$, and a $9 \mu \mathrm{L}$ aliquot of supernatant from centrifugation for $15 \mathrm{~min}$ at $16200 \mathrm{x} \mathrm{g}$ was used directly for the polymerase chain reaction (PCR) to amplify the ITS regions of rDNA (about 300-900 bp). The PuReTaqT Ready-To-Go ${ }^{\mathrm{TM}}$ PCR beads [GE Healthcare] was used for PCR reaction with the total volume of $25 \mu \mathrm{L}$. The prime sets ITS5-ITS4 were used for amplifying 5.8S rDNA and internal transcribed spacer (ITS) sequences (White $e t a l$. 1990) using the polymerase chain reaction (PCR). PCR products were purified using a DNA purification kit QIAquick PCR columns (Qiagen). The purified PCR products were used as templates for sequencing with an $\mathrm{AB}$ PRISMTM BigDye Terminator Cycle sequencing kit, version 3.1 (PE Applied Biosystems, Foster City, CA). The cycle sequencing products were purified using QIAquick Spi Column (Qiagen). The complete sequence of 5.8S rDNA including ITS regions of the rDNA, were sequenced with the primers ITS4 and ITS5 using an ABI PRISM 310 automated DNA sequencer (PEApplied Biosystems, Foster City, CA).

DNA Sequence Analysis. The ITS sequences data were sent to online international DNA database for homology search by the Basic Local Algorithm Search Tool (BLAST) (Altschul et al. 1997). BLAST searches were used to identify new isolates. DNA sequences were aligned with other sequences obtained from the GenBank database using the multialignment program Clustal $\mathrm{X}$ (Thompson et al. 1994). The phylogenetic tree was constructed by Neighbour-Joining method using Kimura two parameter (Sailon 1000 replications (Felsenstein 1985).

\section{RESULTS}

Identification of Yeasts from Apis cerana. We selected 14 out of 35 yeast isolates from the gut of $P C B$ and NCB of $A$. cerana as representative isolates for identification. The representative yeast isolates were selected after twotimes screening, based on their morphological type, and are presented in Table 1. Yeast isolates with the sam morphotype were omitted from this table.
Molecular identification of the representative yeast isolates based on their internal transcribed spacers (ITS) regions of ribosomal DNA sequences data showed that they we apicolat Cand to Kodamaea ohmeri, Metschnikowia sp. and Yarrowia lipolytica. The homology of the sequences of some isolates how a low degree of similarity to their closest related species (homology <98\%) (Table 1). Three isolates have $99 \%$ homology of their sequences to their closed related .

The Aureobasidium closely-related isolates were found in both PCB and NCB (Table 1). On the other hand, Candida cf. apicola, Candida. cf. azyma, Y. lipolytica, K. ohmeri and Metschnikowia sp. closely-related isolates were found only in PCB, while C. cellae and Dothioraceae sp. were only isolated from NCB. The frequency of occurrence of yeast isolates from PCB and NCB is presented in Table 2. Candida cf. apicola has the highest frequency of occurrence in $\mathrm{PCB}(33 \%)$, followed by $K$. ohmeri closely related isolates with frequency of occurrence of $22 \%$. In NCB, the highest

Table 1 Identification of yeast isolates from pollen- and nectar-
collecting bees of $A$ Ais cerana foraging on Jatrophaintegerrima

\begin{tabular}{|c|c|c|}
\hline Isolate codes & $\begin{array}{c}\text { Closely related species } \\
\text { (\% homology) }\end{array}$ & Bee typ \\
\hline P 1 M (A) & Candida cf. apicola (98\%) & PCB \\
\hline P 1 M (B) & C. cf. apicola $(99 \%)$ & РСB \\
\hline P 1 M (C) & Kodamaea ohmeri $(98 \%)$ & РСB \\
\hline P 1 M (D) & C. cf. azyma $(99 \%)$ & РСB \\
\hline P3 M (2) & Aureobasidium pullulans $(96 \%)$ & NCB \\
\hline P 3 M (3) & C. cellae $(91 \%)$ & $\mathrm{NCB}$ \\
\hline P 3 M (4) & C. cellae $(92 \%)$ & $\mathrm{NCB}$ \\
\hline P3 M (5) & C. cellae $(89 \%)$ & $\mathrm{NCB}$ \\
\hline B 2 M (A) & Dothioraceae $(98 \%)$ & $\mathrm{NCB}$ \\
\hline B $5 \mathrm{M}$ & Metschnikowia sp. (87\%) & РСB \\
\hline KM 1 M & C. cf. apicola $(98 \%)$ & РСВ \\
\hline KM 2 M (A) & Yarrowia lipolitica $(99 \%)$ & РСB \\
\hline KM 3 M (B) & A. pullulans $(98 \%)$ & РСB \\
\hline IK $2 \mathrm{M}(\mathrm{A})$ & K. ohmeri $(97 \%)$ & PCB \\
\hline
\end{tabular}

$\mathrm{PCB}=$ pollen-collecting bee; $\mathrm{NCB}=$ nectar-collecting bee.

Table 2 The frequency of occurrence of yeast isolates from pollen- and
nectar-collecting bees of $A$ pis cerana foraging on Jatropha integerrima Frequency of occurrence

\begin{tabular}{cc}
\multirow{2}{*}{ Closely-related Species } & \multicolumn{2}{c}{$\begin{array}{c}\text { Frequency of occurrence } \\
(\%) \text { in }\end{array}$} \\
\cline { 2 - 3 } & PCB $\mathrm{NCB}$ \\
\hline
\end{tabular}

\begin{tabular}{lcc} 
& PCB & NCB \\
\hline Aureobasidium pullulans & 11 & 20 \\
Candida cf. apicola & 33 & - \\
C. cf. azyma & 11 & - \\
C. cellae & - & 60 \\
Dothioraceae & - & 20 \\
Kodamaea ohmeri & 22 & - \\
Metschnikowia sp. & 11 & - \\
Yarrowia lipolitica & 11 & - \\
\hline PCB $=$ pollen-collecting bee; $\mathrm{NCB}=$ nectar-collecting bee.
\end{tabular}




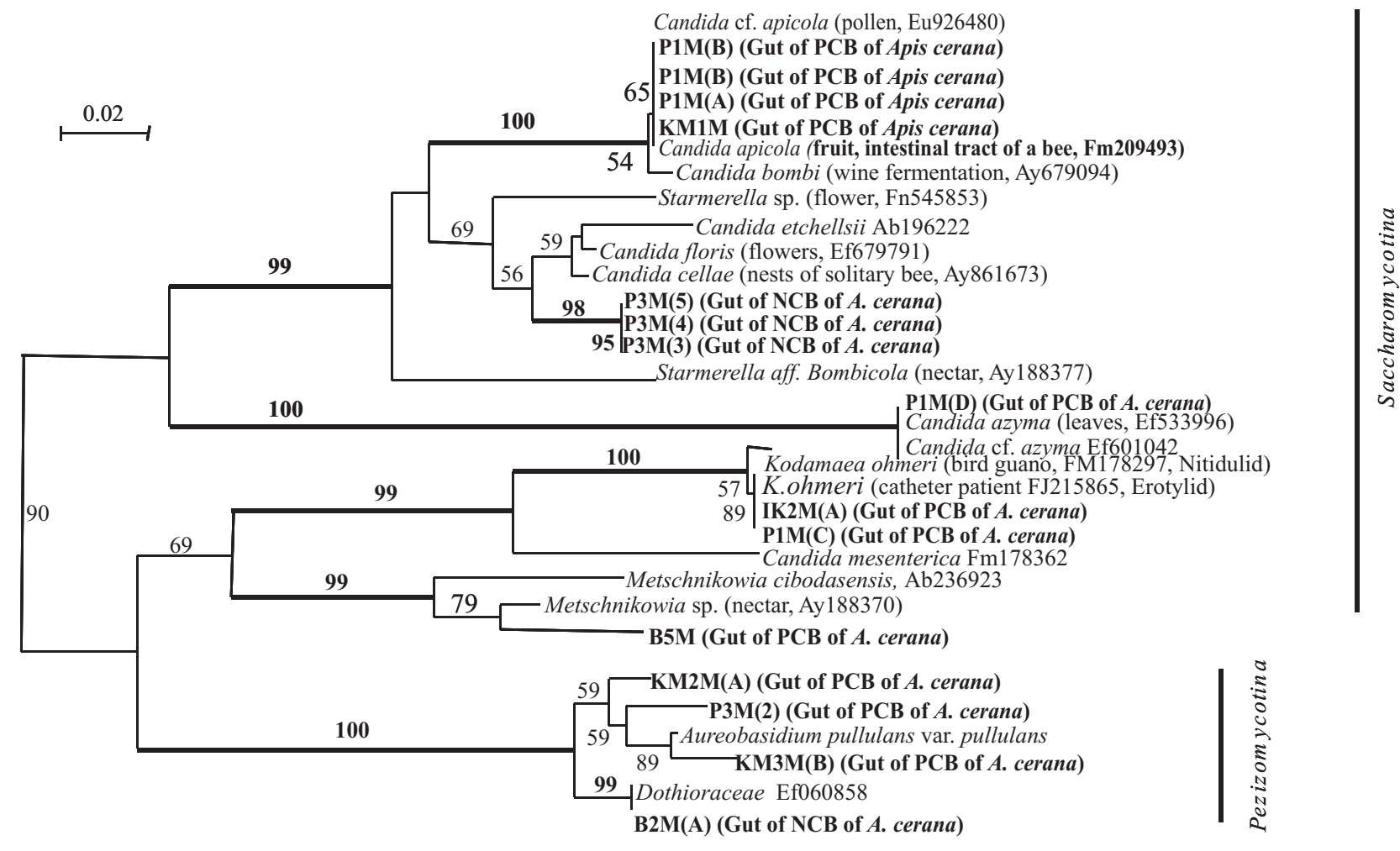

Fig 1 Unrooted phylogenetic tree of yeast isolates from Apis cerana foraging on Jatropha integerrima and their closely related species and substrates
here found. Yeasts from $A$. cerana were grouped into the sub-phyla Saccharomycotina and Pezizomycotina of the phylum As comycota. Yeasts isolated fro where found. Yeasts from $A$. cercana were grouped into the sub-phyla Saccharomycotina and Pezizomycotina of the phylu
this study are indicated by bold. The tree was constructed by Neighbour-Joining method based on TTS region sequence data.

frequency of occurrence belongs to $\mathrm{C}$. cellae closely related isolates $(60 \%)$

Phylogenetic Placement. The phylogenetic placement of yeast isolates within the phylum of Ascomycota and their relationship to neighboring species is presented in Fig 1 . This tree shows that all yeasts from $A$. cerana were grouped into the sub-phyla Saccharomycotina and Pezizomycotina of the phylum Ascomycota. Some species of yeasts from $A$. cerana isolated in this study were clustered with other yeast associated with bees or other insects obtained from the GenBank database. Other species from $A$. cerana were closely related to yeasts associated with flower, nectar, leaves or other substrates.

\section{DISCUSSION}

All yeasts isolated from the gut of $A$. cerana found in this Ady are phylogenetically closely related to yeas within the phylum Ascomycota. The genera of Aureobasidium and Dothioraceae belong to the class Euascomycetes of and Dothioraceae be sub-phylum Pezizomycotina. Other species, i the sub-phylum Pezizomycotina. Other species, i.e. Candida Metschnikowia sp and $Y$ lipolytica belong to the class Hemiascomycetes of the sub-phylum Saccharomycoting. Lachance et al. (2001b) mentioned that ascomycetous yeasts from the order Saccharomycetales are the dominan yeasts in beetle-flower-yeast system. Brysch-Hetzberg (2004) also found that similar ascomycete species predominated in both flowers and bees. The Ascomycota were able to tolerate high sugr concentrations while Basidiomycota were not.
Yeasts have been isolated frequently from the gut or surface of insects that feed on a valety of materias, including basidiomycete fruiting bodies, woody substrates, ephemeral flowers and nectar exudates (Suh and Blackwell 2004; Nguyen et al. 2007; Nakase et al. 2009). Some yea species found in this study have been reportedly isolated from bees or other insects associated flowers. Lachance al. (2001b) collected $A$. pullulans and C. azyma from bees. They found $A$. pullulans and C. azyma were among the most frequently isolated yeasts from the flower-beetle-yea system. Aureobasidum sp. was also isolated from honeybee A. mellifera (Johnson et al. 2005). Rosa et al. (2003) found A. pullulans and K. ohmeri from stingless bee species, and strains identified as members of the $C$. apicola complex fro a stingless bee Melipona quadrifasciata. Stratford et at. (2002) suggested strongly that $C$. apicola was one of severa east species that is primarily associated with the Aculeate (bees and wasps). In their study carried out in Atlantic rai orest of Brazil, Pimentel et al. (2005) isolated C. cellae from pollen-nectar provisions of a solitary bee Centris tarsata. The yeast genus Metschnikowia is the predominant genus both bees and flowers. Most species of Metschnikowia were found in the nectar or corolla of flowers or in decaying fruit or plant tissue; they are transmitted to new niches by insects, such as bees and drosophilids (Lachance et al. 2001a). According to Hagler et al. (1993), the genus Metschnikowia isolated from terrestrial habitats is typically associated with flowers or fruits and insects.

The present study shows that the yeast species isolated from A. cerana differ from yeast species previously reported by Shandu and Waraich (1985). The difference might be due to a distinct origin of $A$. cerana, geographically and taxonomically at the sub-species level, and/or their visite flowers. Our study revealed that a specific community of yeasts could be found in the gut of $A$. cerana native to Indonesia and foraging mainly on the flowers of $J$. integerrima. Manson et al. (2007) mentioned that the composition of the yeast community is highly dependent on the types of insects involved. In his study, Brysch-Hetzberg (2004) concluded that the attractiveness of plants to the flower-visiting insects appears to have had a greater impact on the abundance and frequency of yeasts in the nectar of different plant species.

Our study also found different yeast communities to be O $\mathrm{PCB}$ and $\mathrm{NCB}$ was Aureobasidium closely-reded species. The study shows the occurrence of specific yeast specis CB and $\mathrm{NCB}$. B s on the freque apicola (33\%) in $\mathrm{PCB}$ and $\mathrm{C}$. cella closely retated isoles (60\%) in NCB, we assume there is an assocition between (6) by be becies a. (2002) a so speculed that insects may form sthe nord . (202) also specch a $C$. Hower, we the che the ide

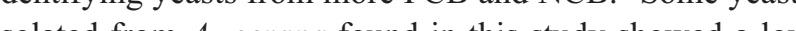
cor (hece simity the the

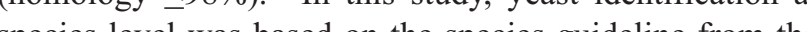
W whe sugita et al. (199). The isolate was assigned to a species if the sequence revealod a lo re of several new taxa of yeasts associated with A. cerana. We Some of the yeats secies ford in the sely are Some the yeasts species found in this study are consistent with the previous studies on bee-floweral. (2001a) and Stratford et al. (2002) believe that the . (2001a) and Steen the functional relationship betwe yeasts and bees as supported by phylogentic evidence. Sun et al. (2005) found ho

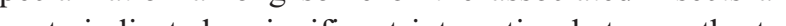
significant interaction between the two group organism

Geres that bees use yeasts to proce polen before it is suitable as a food. Fermentation has been the suspected means of transforming pollen into bee bread. nects, principally nitidulid beellos and drosophitid fics, are vector of a highly specific yeast community that may 2001b; food for the larvae of the insects (Lachance et al. was bachance and Bowles, 2002). Aureobasidium sp. is the causative agent of the brood disease chalkbrood in $A$. mellifera larvae (Johnson et al. 2005). At present, yeasts are implicated in bee nutrition, but there may be additional roles of yeasts in the bee life history.

\section{ACKNOWLEDGEMENTS}

The authors gratefully acknowledge the financial support received from the Faculty of Mathematics and Natural Sciences, University of Indonesia (Hibah Settila FMIPA UI 2008) to WS, and University of Indonesia (Riset Unggulan UI) to $\mathrm{AB}$ (contract no. 715/DRPM-UI/A/N1.4/2009). Thanks also to the Center of Excellence Indigenous Biological Resources-Genome Studies, University of Indonesia for laboratory facilities and Novia Rachmayanti for her assistance during sampling, isolation and molecular analysis.

\section{REFERENCE}

Altschul SF, Thomas LM, Schaffer AA, Zhang J, Zhang Z, Miller W,
Lipman DJ. 1997. Gapped BLAST and PSL-BL AST: 2 ew gener Lipman DJ. 1997. Gapped BLAST and PSI-BLAST: a new generation Batra LR, Batra SWT, Bohart GE 1973. The Mycofflora of domesticated and wild bees (Apoidea). Mycopathol Mycol Appl 49:13-44.
Brysch-Hetzberg M. 2004. Ecology of yeasts in plant-bumblebee mutualism in Central Europe. FEMS Microb Ecol $50: 87-100$.

iorne RB, Licinio P, DupontJ, de Hoog GS. 2005. Internal transcribed with local and global sequence alignment for black yeasts and their relatives. JClin Microbiol 43:2816-23.

de Vega C, Herrera CM, Johnson SD. 2009. Yeasts in floral nectar of some South African plants: quantification and associations with pollinato enstein J. 1985. Confidence limits on phylogenies: an approach using

the bootstrap. Evolution 39:783-91.
Gilliam M. 1997. Identification and roles of non-pathogenic microflora associated with honey bees. FEMS Microbiol Lett 155:1-10. Hagler LCM, Hagler AN, Kurtzman CP. 1993. Phylogeny of Metschnikowia species estimated from partial rRNA sequences. Int $\mathrm{J}$
Syst Bacteriol $43.368-73$

ames SA, Collins MD, Roberts IN. 1996. Use of an rRNA internal transcribed spacer region to distinguish phylogenetically closely
related species of the genera Zygosaccharomyces and Torulaspora. Int J Syst Bacteriol 46:189-94.

Jhnson RN, Zaman MT, Decele MM, Siegel AJ, Tarpy DR, Siegel EC, Starks PT. 2005. Multiple microorganisms in
evidence and implications. JApic Res 44:29-32.

uurtzman CP. 2001. Six new anamorphic ascomycetous yeasts near Candidatanzawaensis. FEMS Yeast Res 1:177-85,

Weots Messchnikowia dekortorum, two new large-spored yeast species
associated with floricolous beetles. FEMS Yeast Res $2: 81-6$. Lachance MA, Starmer WT, Phaff HJ. 1990. Metschnikowia hawaiiensis
sp. nov., a heterothallic haploid yeast from Hawaiian morning glory and associated drosophilids. Int J Syst Bacteriol 40:415-20. continentalis var. continentalis and Metschnikowia hibisci, new heterothallic haploid yeasts from ephemeral flowers and associated achance MA, Starmer WT, Rosa CA, Bo

DH. 2001a. Biogeography of the bowts of ephemeral flowers and their insects. FEMS Yeast Res 1:1-8.

Lachance MA, Bowles JM, Kwon S, Marinoni G, Starmer WT, Janzen DH. 2001b. Metschnikowia lochheadii and Metschnikowia drosophilae,
two new yeast species isolated from insects associated with flowers. two new yeast species isol
Can JMicrobiol 47:103-9. 
Lachance M-A, Ewing CP, Bowles JM, Starmer WT. 2005. Metschnikowia hamakuensis sp. nov., Metschnikowia kamakouana sp. nov. and
Metschnikowia mauinuiana sp. nov., three endemic yeasts from Hawaiian nitidulid beetles. Int J Syst Evol Microbiol 55:1369-77. Manson JS, Lachance M-A, Thomson JD. 2007. Candida gelsemii sp. poisonous Carolinajessamine. Antonie van Leeuwenhoek 92:37-42. Nakase T, Jindamorakot S, Ninomiya S, Imanishi Y, Kawasaki H. 2009. Candida wancherniae sp. nov. and Candida morakotiae sp. nov, two Gen Appl Microbioio 55:93-100

insect-associated yeast clades isolated from Neuroptera and other insects. Mycologia 99:842-58.
mentel MRC, Antonini Y ,

Coel MRC, A A the Starmereella clade associated with solitary bees in the Atlantic rain forest of Brazil. FEMS Yeast Res 5:875-9.

Rosa CA, Lachance M-A, Silva JOC, Teixeira ACP, Marini MM, Antonin , saitou N, Nei M. 1987. The neighbor

reconstructing phylogenetic trees. Mol Biol Evol $4: 406-45$. Shandu DK, Waraich MK. 1985. Yeasts associated with pollinating bee

genomic DNA for PCR. Hayatioid 1022-4aration of fungal and bacterial Stratford M, Bond CJ, James S, Roberts IN, Steels H. 2002. Candida davenportii sp. nov., a potential soft-drinks spoilage yeast isolated from
Sugita T, Nishikawa A, Ikeda R, Shinoda T. 1999. Identification of medically relevant Trichosporon species based on sequences of internal
transscribed spacer regions and construction of a database for Trichosporon identification. JClin Microbiol $37: 1985-93$.
suh S-O, Blackwell M. 2004. Three new beetle-associated yeast species in
the Pichiaguilliermondii clade. FEMSY Yeast Res 5-87 -95. Suh S-O, McHugh JV, Pollock DD, Blackwell M. 2005. The beetle gut: a hyperdiverse source of novel yeasts. Mycol Res 109:261-5.
Teixeira ACP, Marini MM, Nicoli JR,Antonini Y, Martins RP, Lachance Mleixeira ACP, Marini MM, Nicoli J,,Antonini Y, Martins RP, Lachance MA, Rosa CA. 2003. Starmerella meliponinorum sp. nov., a novel Evol Microbiol 53:339-43. Thompson ID, Higgins DG, Gibson TJ. 1994. CLUSTAL W: improving
the sensitivity of progressive multiple sequence alignment through the sensitivity of progressive multiple sequence alignment through choine Nucleic Acid Re

Unal S, Yaman M, Tosun O, Aydin C. 2009. Occurrence of Gregarina
typographi (Apicomplexa, Gregarinidae) and Metschnikowia wpographi (Ascomycota, Metschnikowiaceae) in Ips sexdentatus (Turkey). JAnim Vet Ady 8.2687-91 ite TJ, Bruns T, Lee S, Taylor J. 1990

sequencing of fungal ribosomal RNA genes for phylogenentics. In: Innis MA, Gelfand DH, Sninsky JJ, White TJ, editors. PCR Protocols: a guide to methods and applications. San Diego: Academic Pr.p $315-22$.
Zacchi L, Vaughan-Martini A. 2003. Distribution of three yeast and yeastlike species within a population of soft scale insects (Saissetia oleae) as a function of developmental age. Ann Microbiol 53:43-6. 